\title{
Cognitive task complexity effects on L2 writing performance: An application of mixed-methods approaches ${ }^{1}$
}

\author{
Mahmoud ABDI TABARI ${ }^{a *}$, Toni A. IVEY ${ }^{a}$ \\ ${ }^{a}$ Oklahoma State University, Stillwater, OK, USA \\ *Corresponding author: abditab@okstate.edu
}

\section{ABSTRACT}

This paper provides a methodological review of previous research on cognitive task complexity, since the term emerged in 1995, and investigates why much research was more quantitative rather than qualitative. Moreover, it sheds light onto the studies which used the mixed-methods approach and determines which version of the mixed-methods designs was frequently used. The results reveal that many studies in the field of cognitive task-based research used quantitative rather than qualitative experimental design to collect and interpret their findings. These studies were more oriented to post-positivism supported by an objectivist epistemology. However, limited studies utilized mixed-methods approach to consider the effects of cognitive task complexity on linguistic performance in L2 context. The theoretical perspective behind these studies was pragmatism. The mixed-methods studies only used the explanatory sequential design to collect data and interpret their findings while other versions of the mixed-methods research designs were left undefined. To conclude, the paper identifies the current gap in methodology of the studies and offers recommendations for how to obtain more comprehensive and generalizable findings by utilizing other versions of the mixed-methods studies.

Keywords:

cognitive task complexity; language performance; mixed-methods approach.

\section{RESUMEN}

Este artículo ofrece una revisión metodológica de investigaciones previas sobre la complejidad de tareas cognitivas, desde que surgió término en 1995, e investiga por qué tanta investigación era más cuantitativa que cualitativa. Por otra parte, arroja luz sobre los estudios que utilizaron el enfoque de métodos mixtos y determina cuál versión de los diseños de métodos mixtos se utilizaba con frecuencia. Los resultados revelan que muchos estudios en el campo de la investigación basada en la tarea cognitiva usaban un diseño experimental cuantitativo más que cualitativo para recoger e interpretar sus resultados. Estos estudios se orientan más al postpositivismo apoyado por una epistemología objetivista. Sin embargo, pocos estudios utilizaron el enfoque de métodos mixtos para considerar los efectos de la complejidad de la tarea cognitiva en el desempeño lingüístico en contexto de L2. La perspectiva teórica detrás de estos estudios fue el pragmatismo. Los estudios de métodos mixtos sólo utilizan el diseño secuencial explicativo para recoger datos e interpretar sus resultados, mientras que otras versiones de los diseños de investigación de métodos mixtos se quedaron sin definir. Para concluir, el documento identifica la brecha actual en la metodología de los estudios y ofrece recomendaciones sobre cómo obtener resultados más amplios y generalizables mediante la utilización de otras versiones de los estudios de métodos mixtos.

Palabras claves:

complejidad de la tarea cognitiva; actuación lingüística; enfoque de métodos mixtos.

\section{INTRODUCTION}

Research to date has given increasing attention to cognitive task complexity in the field of task-based language learning and teaching. There is a growing body of research on the effects of cognitive task complexity on linguistic performance in second language (L2) writing such as Ellis and Yuan (2004), Farahani and Meraji (2011), Heidari-Shahreza, Dabaghi, and Kassaian (2011), Kim (2009), Kuiken and Vedder (2007, 2008), Ong and Zhang (2010), Philip, Oliver, and Mackey (2006), Rahimpour and Hosseini (2010), Salimi, Dadaspour, and Asadollahfam (2011), Wigglesworth and Storch (2009), and Sasayama (2011). These studies use quantitative experimental design to interpret their findings, while very little research, giving priority to participants' perceptions and feelings, employs qualitative experimental design (Tavakoli, 2009). The number of studies in the area of cognitive task complexity which use mixed-methods research to collect data and interpret the results are very few (Ellis \& Yuan, 2004; Heidari-Shahreza et al. 2011; Kim, 2009; Sasayama, 2011). The present study is a content-based analysis and it addresses the content of cognitive task complexity through evaluation practices. More importantly, this study attempts to discover how a coherent interaction between philosophical and methodological assumptions effectively contributes to developing cognition through language. In particular, there are three central purposes used to tap the above-mentioned issues: First, this study provides a methodological review of other studies on

\footnotetext{
${ }^{1}$ We would like to express our sincere thanks to the anonymous reviewers for their suggestions and contributions to this article, and Jonathan A. Cannon for his help with the draft of the article.
} 
cognitive task complexity and considers the reasons why these studies were more oriented to quantitative than qualitative approaches. Second, it sheds light onto the studies that use the mixed-methods approach and highlights which version of the mixed-methods designs is frequently utilized to justify the effects of cognitive task complexity on linguistic performance in L2 context. Lastly, through a consideration of the literature, it tries to recognize the gap in methodology of the studies that were searched for over the past two decades. To achieve these goals, the present study strives to answer the following research questions:

- Q1: What are methodological trends in cognitive task-based research?

- Q2: What new understandings can be gained by choosing a mixed-methods approach with a pragmatistic worldview?

As already mentioned, the current problem is that many studies in the field of cognitive task complexity are quantitative-oriented and do not address the question of learners' perceptions and feelings about a task. Previously, these studies primarily explored how the learners perform the task in different conditions and assessed their language performance in terms of fluency, accuracy, and complexity. It is hypothesized that a mixed-methods approach can fill in the methodological gap and also enable researchers to collect two sets of data, both quantitative and qualitative, and provide more comprehensive and generalizable findings. In addition, it is assumed that, other than the explanatory sequential design, other versions of the mixed-methods designs can help obtain more extensive findings and compare them to other studies where relevant.

\section{Literature Review}

The researchers used Crotty's (1998) model as the theoretical basis for this study in order to portray a general picture of the studies on cognitive task complexity and L2 writing performance, and analyze each study in terms of epistemology, theoretical perspective, methodology, and research methods. To grasp an in-depth understanding of these interconnected elements in the research process, we quoted a useful definition of each element proposed by Crotty (1998). He identifies four elements that constitute any process of research: epistemology, theoretical perspective, methodology, and methods. He defines epistemology as "the theory of knowledge embedded in the theoretical perspective and thereby in the methodology" (p. 3). In his terms, theoretical perspective is "the philosophical stance informing the methodology and thus providing a context for the process and grounding its logic and criteria" (p. 3). Crotty states that methodology is "the strategy, plan of action, process or design lying behind the choice and use of particular methods and linking the choice and use of methods to the desired outcomes" (1998, p. 3). The fourth element that Crotty (1998) outlines as part of the research process is methods. He terms methods as "the techniques or procedures used to gather and analyze data related to some research question or hypothesis” (p. 3).

The epistemology behind cognitive task complexity is objectivism because it views the mind as a reflection of environment, producing mental representations of the real world that require a conformity with it. Objectivists believe there is only one single reality that is an absolute fact. In their opinions, our world is independent of our perceptions, attitudes, and emotions to which our thoughts should correspond if our thoughts are to be absolute and right. Therefore, objectivists disagree with the idea that reality is shaped by our perceptions, thoughts, values, and social conventions. Personal beliefs and opinions do not determine the nature of reality, nor will they change what reality is. These beliefs or opinions either agree with the nature of reality, or they do not correspond it. Drawing upon principles of objectivism, cognitivists consider the mind as an information-processing system and how humans possess the information-processing capacity. Duffy and Jonassen (1992) believe that the informationprocessing view highly relies upon the underpinnings of an objectivist epistemology and justifies this claim by expounding that existence of information and the way that information is acquired and processed are independent.

The theoretical perspective of cognitivists is based on post-positivism, which approximates a single reality with observation and experiment because they are not absolutely certain about it. Post-positivists focus on the importance of values, desires, and passion in research. From this perspective, researchers should have an ability to look at the reality as a whole and possess a distanced perspective. However, as Eagleton noted (2003, p. 135), this type of objectivity differs from "just the facts" or "judging from nowhere", which is bereft of context. It demands a fair amount of passion, judgment, self-thinking, and self-discipline, which are in tandem with dialogue and

Abdi Tabari, M. \& Ivey, T. A. (2015). Cognitive task complexity effects on L2 writing performance: An application of mixed-methods approaches. Latin American Journal of Content and Language Integrated Learning, 8(1), 55-65 
discussion. Unlike positivists who try to discover the reality hidden in the participants' mind, post-positivists endeavor to change the predictable sequences that happen in traditional interviews and stimulate applicable prior knowledge of the participants.

Although constructivism is considered as the theoretical perspective of constructionism, cognitivists give less priority to it because they focus more on individuals rather than groups. The collective participants' interpretations of social events or stereotypes help understand multiple realities rather than a single reality. Cognitivists occasionally use the qualitative method to offer an extensive analysis including the first-hand account of individuals' mental processes and justify their initial findings. They believe that reality exists through the participants' observations and interpretations, but social constructivists claim that reality shapes through environment and the constant interaction between individuals and society.

Cognitivists mostly employ the quantitative method to analyze the collected data. However, it is believed that their philosophical assumptions are too puristic and the essence of reality that is determined by participants and their subjective attitudes has received very little attention. Therefore, there is a need to move from objectivism to social constructionism. This transition allows researchers to gain deeper insights of individuals' thoughts and attitudes to justify their quantitative results.

Keep in mind these theoretical perspectives are independent of each other; however, a research study is most likely to include both perspectives. A researcher can work on each phase of the study separately in terms of theoretical perspective, methodology, and research method, but $s /$ he has to set his/her priorities in advance and know how to move from one theoretical perspective to another, from a research methodology to another, and from a research method to another. Since much mixed-methods research is supported by pragmatism as the best theoretical perspective, many researchers use it for the mixed-methods research, which includes multiple paradigms at the same time rather than focus on two independent theoretical perspectives in each phase of the study. Pragmatism gives priority to the outcomes of research, the utilization of multiple research methods to collect data, and the research questions that are addressed in a study. Therefore, it is a flexible and pluralistic perspective for the mixed-methods research. In this theoretical perspective, the focus is placed more on collaboration between researcher and active participants such that both parties work together to co-construct knowledge, form research questions, collect and interpret the data, and finally put the findings into practice.

At the level of methodology, cognitivists usually use experimental research or survey research as the methodology of study because it allows them to reach a level of certainty and objectivity, and provide empirical evidence for their theoretical assumptions. They often use experimental research or survey research as the methodology of the study. Either survey or experimental research enables researchers to reach a certain level of certainty, and provide empirical evidence for the principles of cognitivism, such as cognitive task complexity. Following an objectivist epistemology and a post-positivist worldview, cognitive researchers are leaning too much on the quantitative rather than the qualitative strand. Since the methodology of cognitive studies is more quantitative-oriented, the research methods are often sampling, measurement, and scaling. However, there are very few cognitive studies that utilize qualitative research methods such as observation, interview, focus group, and case study.

\section{Cognitive task complexity}

Kuiken and Vedder (2007) stated that task-based language teaching includes four basic approaches: 1) Psycholinguistic, interactional approach, 2) Social interactive approach, 3) Cognitive information processing approach, 4) Structured-focused approach. In this paper, the focus is placed on the third approach, "cognitive information processing approach". Within this approach, there are two competing models that justify cognitive task complexity effects on linguistic performance in terms of fluency, accuracy, and complexity. These two wellknown models are: Robinson's (2001, 2003) Cognition Hypothesis and Skehan's (1998) Limited Attentional Capacity Model. In comparison to other cognitive models in which task sequence and organization in an instructional program were comparatively indeterminate, these two models strive to address key factors that have a significant impact on task selection and sequence in the program. To gain an in-depth knowledge of the two models, a brief summary of each model is provided below.

Abdi Tabari, M. \& Ivey, T. A. (2015). Cognitive task complexity effects on L2 writing performance: An application of mixed-methods approaches. Latin American Journal of Content and Language Integrated Learning, 8(1), 55-65. 


\section{Robinson's model of task complexity}

Robinson (2001) defines task complexity as "the cognitive task features which can be manipulated either to increase or decrease cognitive demands placed on the learners when they perform a task" (p. 29). He states that learners can show an improvement on their performance and fulfill tasks successfully if cognitive degree of complexity in the tasks enhances. In a simple task, learners do not fully attend to all aspects of language performance at the same time, but in a complex task, they have to give their full attention to all aspects of the task in order to complete it. Therefore, their language performance improves as they perform a task bearing a higher cognitive load. In other terms, Robinson (2001) asserted that there is a direct relationship between manipulating cognitive complexity of task and language performance improvement such that learners direct their attention to all aspects of language performance simultaneously as they carry out a difficult task.

In his "Triadic Componential Model," Robinson (2001) considered the mental process of learners when they are performing a task. He concluded that differences in language performance and the capacity of working memory will affect learners' perceptions and attitudes toward the task such that learners whose language proficiency is limited find it difficult to complete the task and as a result, cannot achieve task fulfillment.

In closing, Robinson (2005) mentioned that manipulating the enhancement of cognitive task complexity improves learners' language performance and also contributes to language acquisition process, and finally leads to a striking change in learners' language skills.

\section{Skehan's model of task difficulty}

Skehan and Foster (2001) defined task difficulty as a factor that deals with "the amount of attention the task demands from the participants. Difficult tasks require more attention than easy tasks" (p. 196). According to Skehan (1998), the task difficulty model consists of code complexity, cognitive complexity, communicative stress, and learner factors. Skehan's task difficulty model relies upon information processing theory contending that the capacity of the human mind is limited such that learners, particularly those with low language proficiency level, cannot give their full attention to all aspects of language (i.e. fluency, accuracy, and complexity) simultaneously, thus giving priority to one aspect of language at the expense of others. VanPatten (1990) agreed with the model and reported that learners often fail to direct their attention to fluency, accuracy, and complexity at the same time due to their limited attentional capacity. As a result, they have to channel their attention to one aspect of language at the price of others. Skehan (1998) explained that, manipulating task factors provides information that contributes to creating an instructional model in which all aspects of language performance will be carefully taken into consideration.

Overall, the two models proposed by Robinson (2001), and Skehan and Foster (2001) have different perspectives of cognitive task complexity effects on language performance. On the one hand, Robinson (2001) stated that task complexity benefits in accuracy and complexity; however, it does not have a marked effect on fluency. Therefore, research that manipulates the cognitive load of task complexity will, in turn, aid accuracy and complexity, while at the same time decrease fluency. On the other hand, Skehan (1998) drew upon information processing theory by claiming that "when task demands are high, attention can only be allocated to a certain aspect of performance to the detriment of others" (p. 73). He also proposed that some effects are general and they will result in a competition between different aspects of language performance. Of the three aspects of language performance, Skehan and Foster (2001) realized the competition between complexity and accuracy. This claim has been advocated by empirical evidence from a large body of research on pre-task planning.

The purpose of this study is two-fold. First, the study considers the trends of cognitive task-based research over the past two decades. Second, it highlights the methodology section of the reviewed studies in order to explore what new understandings can be gained by choosing the mixed-methods approach, which holds a pragmatistic worldview.

\section{METHOD}

This study set out to focus on the concept of cognitive task complexity that emerged in 1995. It explored the effects of cognitive task complexity on L2 textual performance through the review of other studies over the past

Abdi Tabari, M. \& Ivey, T. A. (2015). Cognitive task complexity effects on L2 writing performance: An application of mixed-methods approaches. Latin American Journal of Content and Language Integrated Learning, 8(1), 55-65. 
two decades. Upon searching for articles on cognitive task complexity and L2 written performance in different databases, about 40 articles were found. The epistemology in the majority of the studies reviewed was objectivism and their theoretical perspective was post-positivism. However, there were some mixed-methods studies that used pragmatism as the theoretical perspective. Also, we point out that Ellis and Yuan's (2004) study was the only mixed-methods study that used two independent theoretical perspectives in order to collect both quantitative and qualitative data and interpret their results. Out of approximately 40 articles, we focused on only 11 articles which were very close to the concept of cognitive task complexity and L2 written performance including Ellis and Yuan (2004), Farahani and Meraji (2011), Heidari-Shahreza et al. (2011), Kim (2009), Philip et al. (2006), Ong and Zhang (2010), Rahimpour and Hosseini (2010), Salimi et al. (2011), Sasayama (2011), Tavakoli (2009), and Wigglesworth and Storch (2009). Other studies were not considered for further analysis because the research questions addressed in other studies were not relevant to those we designed to answer in the current study.

We decided to use thematic analysis in order to identify, examine, and report patterns and themes in the collected data. Moreover, we moved beyond this analysis, and interpreted different variables of the research topic. Thematic analysis allowed us to provide detailed and relevant descriptions of our qualitative data and develop deeper understandings of the content. Lastly, we chose thematic analysis as an analytic strategy for qualitative information because it is detached from any specific epistemology or theoretical perspective. Therefore, the selected articles were coded and analyzed according to the elements proposed by Crotty's (1998) model. The final analysis presented here is based on what is described in the studies reviewed.

\section{RESULTS}

Rahimpour and Hosseini (2010) examined the effects of cognitive task complexity on L2 learners' language performance in L2 written narratives. The theoretical perspective of the study was post-positivism such that the researchers approximated the reality with experiment and analysis. To discuss the findings, they used Skehan and Fosters' (2001) model, which emphasized learners' limited attentional capacity. Through a consideration of the model, the researchers provided a strong justification that is in line with their findings. At the level of methodology, they used experimental research and emphasized the quantitative method, which utilizes the oneshot case study design. Rahimpour and Hosseini (2010) collected the quantitative data and interpreted their findings. The results of their study show that the participants produced more fluently written narratives when tasks were cognitively more complex and challenging; however, they could not compose narrative texts which showcase more accurate and complex language. In other words, enhancing the complexity of the tasks did not have any statistically significant effects on the accuracy and complexity of L2 learners' written narratives. The results indicated that task complexity limits the capacity of information processing in L2 learners' minds, so that they prioritize one aspect of language at the expense of another.

Philip et al. (2006) investigated the relationship between different components of task planning and children's linguistic output in a L2 academic context. The theoretical perspective of the study was post-positivism and the researchers knew that there was one single reality, but they could not prove it with an absolute certainty. Therefore, they examined the relationship between variables in order to reach certitude that affirmed the effects of pre-task planning on children's oral performance in the authentic L2 context. The researchers used Skehan and Fosters' (2001) model to justify their findings. In terms of methodology, they performed the experimental research and focused on the quantitative method using the three-group posttest design. Their findings revealed that children provided greater interactional feedback when they had no time or limited time to plan. In addition, pretask planning had limited effects on accuracy and fluency; however, it had a remarkable effect on complexity.

Tavakoli (2009) examined L2 learners' and teachers' views of task complexity and also evaluated to what extent the available frameworks of task complexity represented their perceptions and views. Following the research trend, we believe that the epistemology behind the study was constructionism and the theoretical perspective, which supported the research, was constructivism because the researcher considered how the participants constructed knowledge and interpreted the criteria of task difficulty in a language course. The methodology of the study was based on a case study such that the researcher had a direct, non-participant observation and she audiotaped interviews with focus groups during the study. The results indicated that, although the participants had almost different perceptions of task difficulty, they shared a lot of commonalities in

Abdi Tabari, M. \& Ivey, T. A. (2015). Cognitive task complexity effects on L2 writing performance: An application of mixed-methods approaches. Latin American Journal of Content and Language Integrated Learning, 8(1), 55-65. doi:10.5294/laclil.2014.8.1.6 elSSN 2322-9721. 
terms of the criteria they set for defining and grading task difficulty. These results illustrated how the criteria of the amount of cognitive load, transparency of picture or story, task structure, degree of given information, and availability of background information could relate to the elements proposed in Skehan's task difficulty model.

Salimi et al. (2011) explored the effects of cognitive task complexity utilizing resource-directing traits on linguistic performance in second language (L2) writing. Like other experimental research, the theoretical perspective of the study was post-positivism and the researchers used sampling, measurement and scaling to analyze the quantitative data. The design of the study was a one-shot case study/post-test only. The results show that there was no significant relationship between cognitive complexity and L2 writing performance in terms of fluency and accuracy; however, this relationship was observed for complexity. In the case of complexity, the results were in line with the assumptions of Cognition Hypothesis in that enhancing the amount of cognitive load using resource-directing traits resulted in producing more syntactic language.

Ong and Zhang (2010) investigated the effects of manipulating task complexity using the resource-directing and resource-dispersing traits on fluency and lexical complexity in argumentative writings. The theoretical perspective that lends general support to this study was post-positivism. The researchers used experimental research as the methodology of the study and utilized sampling, measurement and scaling. The design of the study was a randomized pretest-posttest design. The results indicated that, with regard to planning time conditions, increasingly manipulating task complexity resulted in more language fluency (II) and lexical complexity. By providing ideas and macro-structure concurrently, increasing task complexity contributed to more lexically complex language while it did not have marked effects on the two types of fluency (I) and (II). Through the availability of first drafts during revision, increasing task complexity did not lead to a significant increase in fluency and lexical complexity.

Farahani and Meraji (2011) examined the joint effects of resource-directing trait such as $+/-$ planning time and resource-dispersing trait such as +/- Here and Now on 123 L2 learners' written narratives elicited through 12 picture strips. Like other experimental research, this study had the same theoretical perspective, methodology, and research methods. The design of the study was a randomized pretest-posttest design. The participants' written narratives were coded and measured in terms of grammatical accuracy, syntactic complexity, lexical complexity, and fluency. These measures were developed in order to assess the quality of the participants' written narratives. A series of two-way between subjects ANOVAs and the Mann-Whitney U tests were performed on all the measures. The results revealed that the participants who had planning time showed an improvement on grammatical accuracy and also benefited in syntactic complexity. However, the comparisons across the four planning conditions were not statistically significant in the case of lexical complexity. Moreover, the participants in the first and second planning conditions outperformed those in the third and fourth planning conditions with regard to fluency. Also, the impact of manipulating immediacy on fluency was remarkable and the pre-task planners were more fluent than the no planners.

Wigglesworth and Storch (2009) considered the implementation of collaborative writing tasks in the L2 context and compared the textual output of the two groups of L2 learners who produced their texts individually and in pairs. This study used post-positivism as the theoretical perspective and it used experimental research as the basis for the methodology. Sampling, measurement, and scaling were utilized as research methods for data collection and analysis. The design of the study was the posttest-only randomized experimental design. While the pairs were composing their argumentative texts, their interactions were recorded. They were then transcribed for further analysis. To see whether there were any significant differences between the essays composed by the pairs and those generated by the individuals, their written performances were also analyzed in terms of fluency, accuracy, and complexity. The results of this comparison indicated that the pairs showed an improvement on accuracy, but did not significantly influence fluency and complexity. A further analysis of the dialogues in the set of pairs reveal that collaboration enabled the learners to work on different components of writing and also focused on the content of their textual output. Additionally, the results illustrated that collaboration provided the set of pairs with many opportunities to formulate their ideas and also make use of their linguistic knowledge.

The epistemology of the studies that have been considered up to this stage of exploration is objectivism and the theoretical perspective of these studies comes from post-positivism. The methodology of the studies is mainly based on experimental research or survey research. These studies are quantitative-oriented and data are collected mixed-methods approaches. Latin American Journal of Content and Language Integrated Learning, 8(1), 55-65. 
in a variety of formats, including sampling, measurement, and scaling. In the next stage of exploration, we will focus on the mixed-methods studies that have been conducted in the area of cognitive task complexity and L2 textual performance. These studies include Ellis and Yuan (2004), Heidari-Shahreza et al. (2011), Kim (2009), and Sasayama (2011). The research trends of these studies are different from other studies reviewed in this paper and also show new understandings of the topic within the mixed-methods approach supported by a pragmatistic worldview.

Ellis and Yuan (2004) examined differential effects of task planning conditions on linguistic performance in L2 written narratives. The researchers worked on each phase of the study separately in terms of epistemology, theoretical perspective, methodology, and research methods. The epistemology of this study moved from objectivism to social constructionism. The researchers used a post-positivist worldview in order to support the quantitative phase of the study and a constructivist worldview to shield the qualitative phase of the study. This transition from one theoretical perspective to another offers an in-depth analysis of research and provides thorough knowledge of both. By looking at each stage of the study, it became clear that the notation for the study is QUAN $\rightarrow$ qual. In other words, the researchers used the explanatory sequential design to collect the initial quantitative results followed by the second qualitative results. This study gave priority to the quantitative rather than qualitative strand and considered participants' perceptions and feelings to validate and support the initial quantitative results. The results indicated that the pre-task planners showed an improvement on fluency and syntactic variety, but the on-line planners benefited in accuracy. In addition, based on different components of L2 writing processes, the pre-task planners could have a better formulation than the on-line planners, but the latter performed monitoring of the texts better than the former. The "no planners", who were pressured to complete the task, had difficulty in the formulating, executing, and monitoring of their textual output. Moreover, their written narratives made no remarkable progress on fluency, complexity, and accuracy compared to other planning conditions.

Heidari-Shahreza et al. (2011) examined the effects of manipulating task complexity using the dimensions of reasoning demands and the number of elements on the incidence of Lexical-related Episodes (LREs) in EFL learners' interaction. The worldview behind this study was pragmatism. The researchers used the explanatory sequential design, which gives priority to the quantitative rather than qualitative strand. They utilized the qualitative results in support of the initial quantitative results to provide strong empirical evidence for their extensive findings.

The researchers asked the participants to complete two versions of picture narration tasks (simple and complex) and two versions of picture difference tasks (simple and complex). After completing the tasks, the participants were given a questionnaire to explore their perceptions of the tasks. The results indicated that, in the picture narration tasks, the number of lexical and grammatical LREs produced by the high and low-level learners in the complex version of the task were high; however, the results of individual Wilcoxon Signed Ranks tests depicted that only the high-level participants' production was statistically significant. In the picture difference tasks, both high and low-level students showed an improvement on the number of lexical and grammatical LREs in the complex version; nevertheless, only the production of low-level learners was statistically significant.

Kim (2009) investigated the effects of cognitive task complexity on the number of language-related episodes (LREs) generated by L2 students with different English proficiency in peer interaction. Pragmatism, which includes both quantitative and qualitative strands in a single study, was the theoretical perspective of the study. The explanatory sequential design was the design of the study. The researcher collected the quantitative data first and then gathered the qualitative data in order to validate and support the initial quantitative phase of the project.

In this study, the participants were divided into five classes and the pairs were randomly matched. They had the same partner over four tasks (two picture narration tasks and two picture difference tasks). Each pair was asked to perform each task in 15 minutes and then start the following task at the end of the 15 minutes. When they completed all four tasks, they had to fill out a questionnaire in English. Afterwards, the data were transcribed and analyzed by the researcher in order to determine the number of lexical and grammatical LREs over peer interaction.

The results revealed that the low proficiency group generated more LREs in the simple than in the complex picture narration task; however, the high proficiency group produced more LREs in the complex than in the

Abdi Tabari, M. \& Ivey, T. A. (2015). Cognitive task complexity effects on L2 writing performance: An application of mixed-methods approaches. Latin American Journal of Content and Language Integrated Learning, 8(1), 55-65. doi:10.5294/laclil.2014.8.1.6 elSSN 2322-9721. 
simple narration task. As for the picture difference tasks, the low group created more LREs in the complex picture difference task than the simple picture difference task and, somewhat surprisingly, no difference was seen between these tasks by the high group. The results relatively agreed with the assumptions of Cognitive Hypothesis and identified task types and student proficiency as two fundamental factors influencing the degree of cognitive task complexity, resulting in changes in the rate of interactional processes in the L2.

Sasayama (2011) investigated the effects of manipulating enhancement of task difficulty on language performance in both oral and written modes. The theoretical perspective of the study was pragmatism. The design of the study was the explanatory sequential design (QUANT $\rightarrow$ qual) that was implemented in two interrelated phases: the first, major phase included collecting quantitative data and analyzing what they collected and recorded. In order to obtain a better understanding of the initial results in the quantitative phase, the researchers also implemented the qualitative phase. The qualitative phase was designed to justify the initial results in the quantitative phase and thus provide a more precise picture of the findings.

The participants in this study were asked to complete four tasks: two written tasks (simple and complex) and two oral tasks (simple and complex). In the written phase, they had one minute to think about their story and plan what they would write. Then, they typed into an online program called SurveyMonkey (2015). They did the same procedure for both simple and difficult tasks. As for the oral phase, they had to plan their story in a minute and then orally narrate it. Again, they followed the same procedure for both simple and difficult tasks. After completing the four tasks, they were asked to complete a questionnaire. The results of the study indicated that the participants produced more complex language in the difficult written task than the difficult speaking task without de-emphasizing accuracy. In addition, complexity was more consistent to the Cognition Hypothesis than accuracy. More importantly, the accurate language production was more contingent on learners' individual skills than the effects of task difficulty. The results of this study were mixed, such that the complexity of language production was in line with the Cognition Hypothesis; however, the accuracy was at odds with the hypothesis and produced inconsistent findings.

\section{DISCUSSION}

We analyzed 11 studies investigating the effects of cognitive task complexity on linguistic performance in L2 writing. Specifically, we focused on the methodology section of the studies and then examined to what extent the results of the studies are interwoven with philosophical and methodological assumptions, which form the trends of these studies. In order to address the first research question of the study, we revealed that the epistemology of the reviewed studies was either objectivism or constructionism and their theoretical perspective was drawn from post-positivism, claiming that there is one single reality; however, researchers cannot prove it with the utmost certitude and confidence. Post-positivism is the issue of probability instead of certainty and deals with a certain degree of objectivity rather than an utter objectivity. Therefore, researchers tried to approximate the reality and, in turn, reject the hypothesis through observation, experiment, and comparison. The majority of the studies used experimental research or survey research which are quantitative-oriented except for the one by Tavakoli (2009) solely relying on qualitative research. The studies in the area of cognitive task complexity leaned too much on quantitative approaches and also centered on careful observations and measures of variables. These studies drew upon either Robinson's Cognition Hypothesis or Skehan's Model of Task Difficulty in order to provide strong empirical evidence in favor of their findings. At the level of methods, most reviewed studies used sampling, measurement, and scaling. However, there were very few studies that used a mixed-methods approach in the area of cognitive task complexity. We provided a detailed analysis of these studies in terms of epistemology, theoretical perspective, methodology, and methods, and differentiated between Ellis and Yuan's (2004) study and other mixed-methods studies. On the one hand, Ellis and Yuan's (2004) study was strongly supported by two distinct paradigms or worldviews: 1) post-positivism and 2) constructivism. Through the stages of the research process, the researchers moved from post-positivism to constructivism. They tried to apply the principles of postpositivism into the study and seek to approximate the single reality through experiment and objectivity. Subsequently, they directed the trend of the research to constructivism and tried to consider the participants' perceptions and attitudes of the written narrative task. Although the qualitative part of the study helped explain the initial quantitative results, the researchers looked at it as an independent part of the study on its own right.

Abdi Tabari, M. \& Ivey, T. A. (2015). Cognitive task complexity effects on L2 writing performance: An application of mixed-methods approaches. Latin American Journal of Content and Language Integrated Learning, 8(1), 55-65. 
Such an indication points to the fact that they had a transition from one paradigm to another over the course of the research. Additionally, we should mention that the researchers gave weight required to collect the quantitative and qualitative parts of the study, analyze what they gathered and recorded, and sequence the stages at which the two parts of the study were mixed and their results were synthesized accordingly. In this study, mixing occurred at the level of interpretation after the researchers collected both sets of the data and analyzed them sequentially. Then, the quantitative and qualitative results were integrated in the last stage of the research process. On the other hand, other mixed-methods studies such as Heidari-Shahreza, et al. (2011), Kim (2009), and Sasayama (2011) used pragmatism as the best theoretical perspective or worldview, which includes both quantitative and qualitative strands in a single study. Pragmatism removes the dichotomy between post-positivist approach and constructive approach and also deals with both of the theoretical approaches in a study. Through a consideration of the research trends in the studies, we realized that the notation for these studies is QUAN $\rightarrow$ qual. In other words, the studies used the explanatory sequential design to collect the initial quantitative results followed by the second qualitative ones. These mixed-methods studies put the large emphasis on the quantitative rather than qualitative strand; however, they assessed participants' perceptions and feelings to validate and support the initial quantitative results. In comparison to other studies, the mixed-methods studies provided more comprehensive and generalizable findings by collecting a larger pool of quantitative and qualitative data and interpreting them.

To address the second research question of the study, we need to highlight that pragmatism or a move from post-positivism to constructivism within a single study can open up a new perspective of cognitive task-based research. The studies, which solely rely upon post-positivism and objectively collect quantitative data through sampling, measurement and scaling, do not address the question of learners' perceptions and feelings about a task. These studies only explore how the learners perform the task in different conditions and assess their language performance in terms of fluency, accuracy, and complexity. The mixed-methods studies address this problem (Heidari et al., 2011; Kim, 2009; Sasayama, 2011) and use the explanatory sequential design, which includes both objective and subjective knowledge. These studies value participants' views and attitudes over the research process and use the qualitative data in favor of validating and supporting the quantitative data. The mixedmethods studies allow researchers to discover how the participants think about the tasks and employ different cognitive strategies to accomplish them. Needless to say, this qualitative phase of the research is always missing in the studies, relying solely on the quantitative phase. Cognitive constructivists believe that the perceptions and beliefs of the participants are of high value, and thus, encouraging researchers to incorporate the qualitative phase into cognitive studies.

Lastly, the mixed-methods approach enables the researchers to effectively design implemental stages, understand how to synthesize the results of these two parts of the study to address the research questions. More importantly, the researchers have precise mental representations of the mixed-methods strands for their research. The mental representations, which are of high importance in the mixed-methods research, can help them gain deeper insights of the mixed-methods strands and their unique features.

\section{CONCLUSION}

In general, there is a serious need to use the mixed-methods approach in the studies emphasizing the principles of cognitive task complexity. The literature shows that the number of mixed-methods studies is very few, and further research in this regard can fill in the current gap. According to our extensive search for the mixedmethods studies in the field of cognitive task complexity, there are limited studies that employ only one type of the mixed methods designs, namely the explanatory sequential design. To be sure, future research will be able to open up new perspectives of the effects of cognitive task complexity on linguistic performance in L2 context by utilizing other versions of the mixed methods designs. We believe much is to be gained by drawing on insights into the convergent design, the exploratory sequential design, the embedded design, and the multiphase design. Due to paucity of cognitive task studies using other versions of the mixed methods designs, it is very difficult to predict the trend of research and probable findings at the present time. Additionally, researchers should know how to make coherent links between theoretical perspective(s) and mixed-methods research. We should state that this mixing is the most challenging issue that the researchers are currently grappling with and it might be the

Abdi Tabari, M. \& Ivey, T. A. (2015). Cognitive task complexity effects on L2 writing performance: An application of mixed-methods approaches. Latin American Journal of Content and Language Integrated Learning, 8(1), 55-65. 
reason for giving too much attention to the explanatory sequential design, which is more relevant to the principles of cognitivism like cognitive task complexity. In sum, further research, including other versions of the mixed methods research designs, is recommended for researchers in order to obtain more extensive findings about cognitive task complexity and, in turn, compare them to other studies where relevant.

\section{REFERENCES}

Crotty, M. (1998). The foundations of social research: Meaning and perspective in the research process. London: Sage Publications.

Duffy, T. M., \& Jonassen, D. H. (1992). Constructivist and the technology of instruction: A conversation. Hillsdale, NJ: Lawrence Erlbaum Associates.

Eagleton, T. (2003). After theory. New York: Basic Books.

Ellis, R., \& Yuan, F. (2004). The effects of planning on fluency, complexity, and accuracy in second language narrative writing. Studies in Second Language Acquisition, 26(1), 59-84. doi:10.1017/s0272263104026130

Farahani, K. A. A., \& Meraji, S. R. (2011). Cognitive task complexity and L2 narrative writing performance. fournal of Language Teaching and Research, 2(2), 445-456. doi:10.4304/jltr.2.2.445-456

Heidari-Shahreza, M. A., Dabaghi, A., \& Kassaian, Z. (2011). The effects of manipulating task complexity on the occurrence of language-related episodes during learner-learner interaction. Porta Linguarum, 17, 173-188.

Kim, Y. (2009). The effects of task complexity on learner-learner interaction. System, 37, 254-268. doi:10.1016/j.system.2009.02.003

Kuiken, F., \& Vedder, I. (2007). Task complexity and measures of linguistic performance in L2 writing. International Review of Applied Linguistics, 45(3), 261-284. doi:10.1515/iral.2007.012

Kuiken, F., \& Vedder, I. (2008). Cognitive task complexity and written output in Italian and French as a foreign language. Journal of Second Language Writing, 17, 48-60. doi:10.1016/j.jslw.2007.08.003

Ong, J., \& Zhang, J. L. (2010). Effects of task complexity on the fluency and lexical complexity in EFL students' argumentative writing. Journal of Second Language Writing, 19, 218-233. doi:10.1016/j.jslw.2010.10.003

Philp, J., Oliver, R., \& Mackey, A. (2006). The impact of planning time on children's task-based interactions. System, 34, 547-565. doi:10.1016/j.system.2006.08.004

Rahimpour, M., \& Hosseini, P. (2010). The impact of task complexity on L2 learners' written narratives. ELT fournal, 3(3), 198-205. doi:10.5539/elt.v3n3p198

Robinson, P. (2001). Task complexity, task difficulty, and task production: Exploring interactions in a componential framework. Applied Linguistics, 22(1), 27-57. doi:10.1093/applin/22.1.27

Robinson, P. (2003). The cognition hypothesis, task design, and adult task-based language learning. Second Language Studies, 21(2), 45-105.

Robinson, P. (2005). Cognitive complexity and task sequencing: Studies in a componential framework for second language task design. International Review of Applied Linguistics, 43, 1-32. doi:10.1515/iral.2005.43.1.1

Salimi, A., Dadaspour, S., \& Asadollahfam, H. (2011). The effect of task complexity on EFL learners' written performance. Procedia Social and Behavioral Sciences, 29, 1390-1399. doi:10.1016/j.sbspro.2011.11.378

Sasayama, Sh. (2011). Cognition hypothesis and second language performance: Comparison of written and oral task performance. Second Language Studies, 29(2), 107-129.

Skehan, P. (1998). A cognitive approach to language learning. Oxford: Oxford University Press.

Skehan, P., \& Foster, P. (2001). Cognition and tasks. In P. Robinson (Ed.), Cognition and second language instruction (pp.183-205). Cambridge: Cambridge University Press.

SurveyMonkey [Online software]. (2015). Retrieved from http://www.surveymonkey.com/

Tavakoli, P. (2009). Investigating task difficulty: Learners' and Teachers' Perceptions. International fournal of Applied Linguistics, 19(1), 1-25. doi:10.1111/j.1473-4192.2009.00216.x

VanPatten, B. (1990). Attending to form and content in the input: An experiment in consciousness. Studies in Second Language Acquisition, 12(3), 287-301. doi:10.1017/s0272263100009177

Wigglesworth, G., \& Storch, N. (2009). Pair versus individual writing: Effects on fluency, complexity, and accuracy. Language Testing, 26(3), 445-466. doi:10.1177/0265532209104670 


\section{BIODATA}

Mahmoud ABDI TABARI is a PhD student in Education with the emphasis on Literacy at Oklahoma State University (Stillwater, OK, USA). His research interests include second language acquisition, content-based instruction, and second language writing.

Toni A. IVEY is an Assistant Professor of Science Education in the School of Teaching and Curriculum Leadership at Oklahoma State University (Stillwater, OK, USA). She also serves as co-director for the Center for Research on STEM Teaching and Learning. Further, she instructs graduate students in conducting and designing mixed methods research. 